Article

\title{
Surface Energy and Tribology of Electrodeposited Ni and Ni-Graphene Coatings on Steel
}

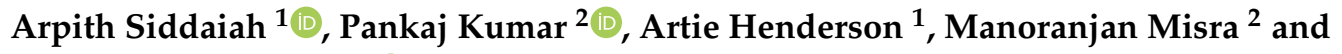 \\ Pradeep L. Menezes $1, *$ (D) \\ 1 Department of Mechanical Engineering, University of Nevada, Reno, Reno, NV 89557, USA; \\ asiddaiah@nevada.unr.edu (A.S.); alhenderson@scu.edu (A.H.) \\ 2 Department of Chemical and Materials Engineering, University of Nevada, Reno, Reno, NV 89557, USA; \\ pkumar@unr.edu (P.K.); misra@unr.edu (M.M.) \\ * Correspondence: pmenezes@unr.edu; Tel.: +775-682-7413
}

Received: 3 August 2019; Accepted: 4 October 2019; Published: 9 October 2019

\begin{abstract}
Composite electrochemical coatings (CECs) are some of the most widely investigated coatings due to its versatility in tailoring physio-mechanical and tribological properties. The effectiveness of the CECs for tribological applications is dependent on the solid-liquid interfaces. The active and passive nature of the contact boundaries for a CEC with a solid/liquid interface is defined by the surface energy of these boundaries. Unless the effect of surface energy on the tribological properties of the CEC are understood, it is not possible to get a holistic picture on properties, such as corrosion and tribocorrosion. The present study investigates the surface energy of optimized nickel $(\mathrm{Ni})$ and $\mathrm{Ni}$-graphene $(\mathrm{Ni}-\mathrm{Gr})$ coatings and their effect on the dynamic friction and wear behavior. It was found that the addition of $\mathrm{Gr}$ to the Ni coating in small quantities could decrease the polar component of surface energy significantly than the dispersive component. The presence of $\mathrm{Gr}$ in the coating was able to reduce the wear while providing low friction. The Ni-Gr coating exhibited low surface energy that includes weak adhesive forces, which can prevent embedding of the wear particles during sliding.
\end{abstract}

Keywords: surface energy; contact angle; friction; wear; graphene; electrodeposition

\section{Introduction}

Composite electrochemical coatings (CECs) are generating significant interest, both in research and in practical applications, particularly in transportation, electrotechnical, food, and textile industries [1-3]. CECs provide a unique technological edge to enhance the mechanical and tribological properties of the surface. Nickel (Ni) is one of the most common metal coatings used to synthesize CECs as it is characterized by superior corrosion resistance, and enhanced mechanical and tribological properties. Recently, graphene has been used in the electrodeposition of $\mathrm{Ni}$ composite coatings known as nickel-graphene (Ni-Gr) coatings for lubrication application. Such coatings are superior in tribological properties as compared to other hard CECs that consist of chromium, boron nitride, zirconium dioxide, PTFE, etc. [3,4]. Gr nanosheets and platelets, due to their layered crystal structure, have been extensively used as lubricant additives to enhance the tribological performance [5-12]. Gr being lightweight, impermeable, atomically thin, wear-resistant, mechanically strong, and inert, is one of the most sought-after materials for a composite coating. In addition, $\mathrm{Gr}$ in the form of nanosheets and platelets have been used as nanomaterial additives in composites and lubricants to enhance the tribological properties [13-18]. In a composite surface coating, graphene has been shown to provide the substrate surface with enhanced wear, corrosion, and hardness properties, which are significant in defining the tribological behavior [19-22]. Further, the presence of graphene in composite surface 
coatings provides high flexibility, which helps compensate micro curvatures or changes in surface roughness of coated substrate while still providing a stable coating. This aspect of graphene composite coatings has made it also suitable for flexible electronics and other electrotechnical applications.

The coating thickness, surface morphology, and mechanical properties vary depending on the electrodeposition process parameters used in the synthesis of Ni-Gr composite coating [23,24]. Additionally, these characteristics also affect the graphene particle distribution in the Ni metal matrix, hence, affect the tribological properties of the coating. The effect of coating characteristics on the mechanical and wear behavior of Ni-Gr composite coatings have been investigated [20,22,23,25]. Most of the focus was given on either wear resistance or corrosion resistance [24]. Coupling these will have a greater impact to understand the performance of the coatings, given that most corrosion-resistant elements are not wear-resistant and vice versa $[20,22,25]$. The tribological and mechanical performance of the coating has been related to the surface energy [26-28]. Fundamental understanding of surface energy on the coating performance is largely unknown [27,29]. It is necessary to understand that these tribological and surface interactions of the coatings affected by surface energy. The surface energy of the coatings has been known to vary with surface composition and topography [30,31]. The present study investigates the effect of the surface energy of $\mathrm{Ni}$ and $\mathrm{Ni}-\mathrm{Gr}$ composite coatings and correlates them to the dynamic friction (henceforth referred to as 'friction' in the text) and wear behaviors. The surface energy effect of $\mathrm{Gr}$ in correlation to the friction and wear behavior of the composite surface will also be studied in this research.

Electrodeposition is one of the most economical and widely used electrochemical method of generating composite surface coatings on metallic substrates [32,33]. The electrodeposition process and modified versions of this process are being used for the fabrication of new devices, but they also have raised some new issues [34,35]. Extensive studies have been conducted for the investigation of effects of electrodeposition parameters, including bath composition, $\mathrm{pH}$, deposition time, additive/surfactants, deposition current density, and bath temperature on the properties of deposited films [36-38]. Bath composition of the composite material and current density deposition parameter are observed to be the two main factors that influence the properties of the CECs, especially in case of pulse electrodeposition [32,39]. This is because they directly influence the composition, structure, and properties of coatings [40]. In most cases, the deposition rate of the coatings is also related to the deposition temperature [41]. It was observed from the previous studies that the composition of the Ni-Gr composite coatings is dependent on the deposition temperature if the remaining bath parameters were fixed $[24,38]$. The present study incorporates this knowledge to electrodeposit $\mathrm{Ni}$ and $\mathrm{Ni}-\mathrm{Gr}$ composite coatings and understand how the surface energy and its various components affect the friction and wear mechanisms.

\section{Materials and Methods}

\subsection{Electrodeposition}

The Ni and Ni-Gr nanocomposite was deposited on the $25 \times 25 \times 15 \mathrm{~mm}^{3} 1045$ steel plate by electrodeposition in their respective $\mathrm{Ni}$ and $\mathrm{Ni}-\mathrm{Gr}$ bath solutions. The detailed material composition of the 1045 steel is given in Table 1. The constituents of $\mathrm{Ni}$ and $\mathrm{Ni}-\mathrm{Gr}$ bath solution are given in Table 2. In addition to similar chemical composition as of $\mathrm{Ni}, \mathrm{Ni}-\mathrm{Gr}$ electrochemical bath consists of $0.1 \mathrm{~g} / \mathrm{L}$ of Gr nanoplatelets [19]. The Gr nanoplates used in this study are 6-8 $\mathrm{nm}$ thick layers with the length ranging from $5-25 \mu \mathrm{m}$. The details of the bath solution are provided in several previous studies, which can vary in the concentration of solvents based on the substrate material [19,42]. Before the deposition process, the steel samples were ground against the sandpapers of grit size 120, 240, 400, 600, 800, and 1000 to remove deep scratches and then were wet polished with diamond suspension polishing mixtures of sizes $15,6,3$, and $0.05 \mu \mathrm{m}$ on a polishing wheel. The polishing of steel was completed with a final polish using colloidal silica. To ensure uniformity of surface finish, each surface was profiled using a 3D optical profilometer (Rtec Instruments, San Jose, CA, USA). The profiling of the surface 
ensured that an average surface roughness $\left(S_{a}\right)$ of $0.1 \pm 0.05 \mu \mathrm{m}$ was obtained after the polishing. The surface roughness measurements were recorded again after the plating process.

Table 1. Material composition and physical properties of 1045 medium carbon steel.

\begin{tabular}{ccccc}
\hline Properties & $\begin{array}{r}\text { 1045 Medium Carbon Steel } \\
\text { (ASTM A108) }\end{array}$ & Properties & $\begin{array}{c}\text { 1045 Medium } \\
\text { Carbon Steel } \\
\text { (ASTM A108) }\end{array}$ \\
\hline & Iron & $98.21 \%-98.85 \%$ & Yield Strength & $530 \mathrm{MPa}$ \\
& Carbon & $0.43 \%-0.50 \%$ & Hardness & $190 \mathrm{HV} 0.5$ \\
Material & Manganese & $0.60 \%-0.90 \%$ & Hardness rating & Medium \\
Composition & Phosphorus & $0 \%-0.04 \%$ & Melting Point & $1427^{\circ} \mathrm{C}$ \\
& Silicon & $0.15 \%-0.30 \%$ & Elongation & $19 \%$ \\
& Sulfur & $0 \%-0.05 \%$ & & \\
\hline
\end{tabular}

Table 2. Constituents of $\mathrm{Ni}$ and Ni-Gr plating bath solution.

\begin{tabular}{cc}
\hline Plating bath Composition & Quantity (g/L) \\
\hline $\mathrm{NiSO}_{4} \cdot 7 \mathrm{H}_{2} \mathrm{O}$ & 26.26 \\
$\mathrm{Na}_{2} \mathrm{SO}_{4}$ & 56.81 \\
$\mathrm{H}_{3} \mathrm{BO}_{4}$ & 18.54 \\
Graphene $(\mathrm{Gr})$ & 0.1 \\
\hline
\end{tabular}

Pure nickel plate (99.5\%) was used as an anode, and a rectangular steel sample was used as a cathode in the electrochemical setup. During the electrodeposition process, the following parameters were set throughout the process: Current density $=5.66 \mathrm{~A} / \mathrm{dm}^{2}$, on-off pulse time $=10 \mathrm{~ms}$, and duty cycle $=20 \%$. The $\mathrm{pH}$ of the bath was maintained between 3.8 and 4.0 at a temperature of $40{ }^{\circ} \mathrm{C}$. A $10 \% \mathrm{H}_{2} \mathrm{SO}_{4}$ was used to decrease the $\mathrm{pH}$ levels as needed. The electrodeposition was carried out for $50 \mathrm{~min}$. These optimized parameters are based on the author's prior work on electrodeposited Ni-Gr coatings [42]. Three samples of each coating were prepared to ensure the repeatability of the process. An average thickness of $\sim 10 \mu \mathrm{m}$ is obtained for all Ni and Ni-Gr coatings.

\subsection{Surface Characterization}

The phase and structural analysis of the Ni and Ni-Gr coatings was performed using Raman spectroscopy (Thermo Fisher Scientific, Thermo Electron North America LLC, Waltham, MA, USA). Raman spectroscopy was carried out using a Thermo Scientific DXR Raman Microscope equipped with a $5 \mathrm{~mW}$ 532-nm laser averaging multiple area map points taken at 100× magnification. The Raman spectroscopy provides wavelength stability with less than $1 \mathrm{~cm}^{-1}$ for over $12 \mathrm{~h}$ period. Spectra were collected in the $1000-3500 \mathrm{~cm}^{-1}$ spectral region, with a grating resolution of $900 \mathrm{lines} / \mathrm{mm}$. The exposure time was $2 \mathrm{~s}$ for 26 scans of $1 \mu \mathrm{m}$ step along the line and three scans over $0.1 \mu \mathrm{m}$ depth at each point.

\subsection{Friction and Wear Tests}

Reciprocating wear tests were performed on the 1045 steel, Ni coating, and Ni-Gr coating. The tests were performed under dry laboratory conditions $\left(20 \% \mathrm{RH}, 24^{\circ} \mathrm{C}\right)$ with a $2 \mathrm{~N}$ constant normal load against a ceramic ball (silicon nitride $(\mathrm{SiN})$ ) of $11.5 \mathrm{GPa}$ hardness. A sliding speed of $5 \mathrm{~mm} / \mathrm{s}$ was maintained for a sliding distance of $4200 \mathrm{~m}$. This test was chosen over other conventional tribological testing as it can provide better insights into the interface kinematics during the reciprocating form of sliding. The experiments were performed on an Rtec Multi-function Tribometer 5000 (Rtec Instruments, San Jose, CA, USA), equipped with a robust high-resolution capacitance load sensor, which can apply the normal load and measure the resulting friction force during sliding. Each test was performed three times to ensure repeatability. After the wear tests, the wear tracks were profiled using the 3D optical profilometer to investigate the wear track, and hence the wear performance. 


\subsection{Hardness Tests}

Nanoindentations tests were performed on all the samples using a Hysitron Triboindenter TI950 (Bruker, Billerica, MA, USA) equipped with Berkovic probe. A maximum force of $10 \mathrm{mN}$ was applied, and the hardness values were measured over ten different locations on the sample. The study reported the average of these hardness values with their standard deviation.

\subsection{Contact Angle and Surface Energy Measurements}

The surface energy and the interfacial tension between the composite surface and the liquids were evaluated using contact angle measurements with rame-hart contact angle Goniometer (rame-hart, New Jersey, NJ, USA). Liquids, namely, distilled water and 3.5\% $\mathrm{NaCl}$ were used in these measurements as these liquids simulate some of the atmospheric conditions, which dictate the corrosion properties of coatings and surfaces. The sessile drop method was used, with distilled water and $3.5 \% \mathrm{NaCl}$ as testing liquids to calculate the surface energy and its polar and dispersive components [43]. The contact angle of the steel, nickel, and nickel-graphene coated surfaces were measured using both liquids. The left and right contact angles of the sessile droplet were recorded and averaged over ten trials to find the average contact angle for each surface. All measurements had a difference in the left and right contact angles less than $2^{\circ}$. These steps ensured the repeatability and reliability of the contact angle measurements.

\section{Results and Discussion}

\subsection{Raman Spectroscopy}

The Raman spectra for $\mathrm{Ni}$ and $\mathrm{Ni}-\mathrm{Gr}$ coatings at $532 \mathrm{~nm}$ laser excited at $5 \mathrm{~mW}$ for the range of $100-3500 \mathrm{~cm}^{-1}$ is shown in Figure 1. In the Raman spectra of Ni coating, there were no significant peaks observed, whereas for the Ni-Gr coating five peaks were observed at $1404 \mathrm{~cm}^{-1}$ (D-mode), $1583 \mathrm{~cm}^{-1}$ (G-mode), $1620 \mathrm{~cm}^{-1}$ (D'), $2775 \mathrm{~cm}^{-1}$ (2D-mode), and $3085 \mathrm{~cm}^{-1}$ (D+G-mode) [44-46]. This confirms the inclusion of $\mathrm{Gr}$ in the electrodeposited $\mathrm{Ni}-\mathrm{Gr}$ composite coating.

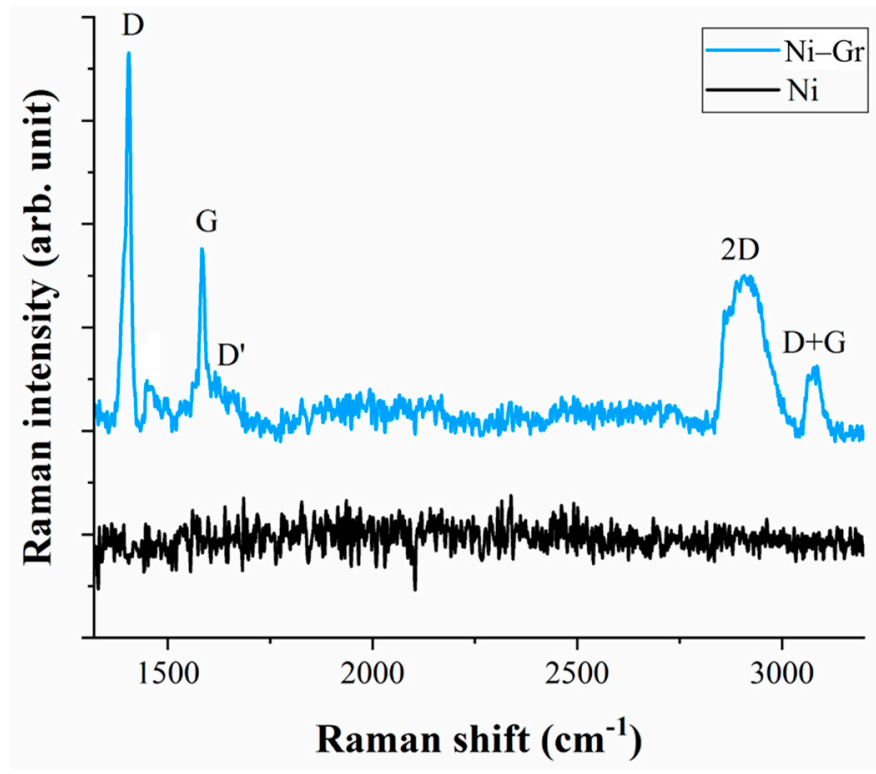

Figure 1. Raman spectra of $\mathrm{Ni}$ and $\mathrm{Ni}-\mathrm{Gr}$ coating on 1045 steel surface with a $532 \mathrm{~nm}$ excitation laser wavelength.

The D and 2D-peak positions are dispersive in nature as they are dependent on the laser excitation energy [45]. The high intensity of the D peak indicates the presence of a large number of nucleation centers on the surface $[47,48]$. The low-intensity $\mathrm{D}^{\prime}$-peak shows that the coating has minimal 
impurities or there are minor surface charges in the Gr. The 2D-band confirms the graphitic sp ${ }^{2}$ phase, and the low intensity of the 2D-peak indicates the multi-layer nature of $\mathrm{Gr}$ used in the present study. The depth-based scans of $0.1 \mu \mathrm{m}$ step on the Ni-Gr coating showed a similar intensity of G-band, as shown in Figure 1. This observation indicates the presence of $\mathrm{Gr}$ in the coatings below the surface. The distribution of $\mathrm{Gr}$ in the coating thickness should enable the coated surface to maintain consistent surface energy even after undergoing wear.

\subsection{Surface Roughness}

Studies $[1,49]$ have shown that the surface roughness of the substrate can directly influence the electrodeposited coating characteristics, such as coating adhesion, and surface finish. Studies have shown that the surface roughness influences the interface toughness, which limits the coating thickness [50]. Hence, the surface roughness can be a defining factor in optimizing the coating characteristics. To understand the effect of graphene on the electrodeposit $\mathrm{Ni}-\mathrm{Gr}$ coating characteristics, it is necessary to achieve consistent surface roughness on the steel substrate before the coating as well as after the coating. The surface profiles of the polished steel substrate are shown in Figure 2a. The thickness and the average surface roughness $\left(S_{a}\right)$ of the electrodeposited $\mathrm{Ni}$ and $\mathrm{Ni}-\mathrm{Gr}$ coatings obtained with the parameters described above are illustrated in Figure $2 b, c$ respectively.

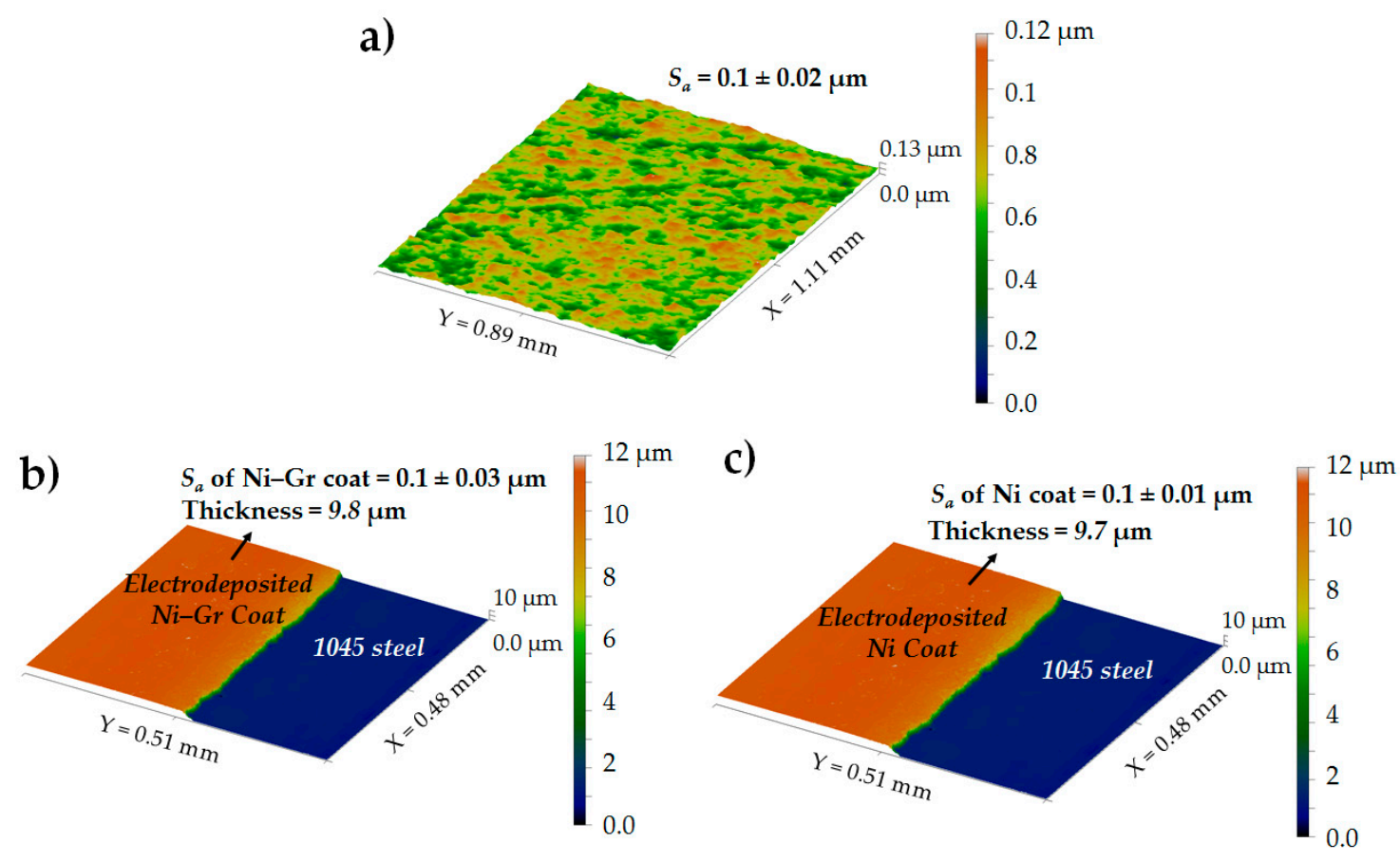

Figure 2. 3D surface profile and average roughness of (a) 1045 steel substrate, (b) Ni coating, and (c) Ni-Gr coating.

The Ni and Ni-Gr coating thickness as obtained were $\sim 9.8$ and $\sim 9.7 \mu \mathrm{m}$, respectively. It can also be seen that the $S_{a}$ of all the samples before and after the coating was within the range of $0.1 \pm 0.05 \mu \mathrm{m}$. Hence, the comparison of these coatings for their tribo-metallurgical behavior was rational. The surface roughness and profile data indicated an excellent finish of electrodeposit coatings with a surface roughness that corresponded to the substrate surface.

\subsection{Surface Energy of the Coatings}

The surface energy of the coatings was calculated using Fowkes theory [51]. Based on Fowkes theory, the interactions between the surfaces and liquids are given as follows: 
Young's equation of surface energy:

$$
\sigma_{\mathrm{S}}=\sigma_{\mathrm{SL}}+\sigma_{\mathrm{L}} \cos \theta
$$

where, $\sigma_{\mathrm{L}}$ is the overall surface tension of the wetting liquid, $\sigma_{\mathrm{S}}$ is the overall surface energy of the solid, and $\sigma_{\mathrm{SL}}$ is the interfacial tension between the surface and the liquids.

Dupre's definition of adhesion energy:

$$
I_{\mathrm{SL}}=\sigma_{\mathrm{S}}+\sigma_{\mathrm{L}}-\sigma_{\mathrm{SL}}
$$

where, $I_{S \mathrm{~L}}$ is the energy of adhesion per unit area between a liquid and a solid surface. By applying the Fowkes theory, adhesive energy between a solid-liquid can be separated into interactions between the dispersive components and between the non-dispersive (polar) components of the two phases. By separating the dispersive and polar components in the above two equations, the primary equation of the Fowkes' surface energy theory is obtained as:

$$
\sqrt{\left(\sigma_{\mathrm{L}}^{\mathrm{D}}\right)\left(\sigma_{\mathrm{S}}^{\mathrm{D}}\right)}+\sqrt{\left(\sigma_{\mathrm{L}}^{\mathrm{P}}\right)\left(\sigma_{\mathrm{S}}^{\mathrm{P}}\right)}=\frac{\sigma_{\mathrm{L}}(\cos \theta+1)}{2}
$$

where, $\sigma_{L}^{P}, \sigma_{L}^{D}, \sigma_{S^{\prime}}^{P}$ and $\sigma_{S}^{D}$ are the polar and disperse components of the surface energy for the liquid and solid. The following values were used to consider the contribution of water and $\mathrm{NaCl}$ solutions to the surface energy: Distilled water surface tension $\left(\sigma_{\mathrm{L} 1}\right)=72.10 \mathrm{mN} / \mathrm{m}\left(\sigma_{\mathrm{L} 1}^{\mathrm{P}}=52.20 \mathrm{mN} / \mathrm{m}\right.$; $\left.\sigma_{\mathrm{L} 1}^{\mathrm{D}}=19.90 \mathrm{mN} / \mathrm{m}\right)$, and $3.5 \% \mathrm{NaCl}\left(\sigma_{\mathrm{L} 2}\right)=73.76 \mathrm{mN} / \mathrm{m}\left(\sigma_{\mathrm{L} 2}^{\mathrm{P}}=22.20 \mathrm{mN} / \mathrm{m} ; \sigma_{\mathrm{L} 2}^{\mathrm{D}}=51.56 \mathrm{mN} / \mathrm{m}\right)[52]$.

The contact angle of the steel, nickel, and nickel-graphene coated surfaces were measured using both liquids. The contact angle of distilled water and 3.5\% NaCl measured on 1045 steel surface, $\mathrm{Ni}$ coating, and Ni-Gr coating is shown in Figure 3.

\begin{tabular}{|l|c|c|c|}
\hline Liquid interface & $\mathbf{1 0 4 5}$ steel & Ni Coat & Ni-Gr Coat \\
\hline \multirow{3}{*}{ Distilled water } & & & \\
\hline $3.5 \% \mathrm{NaCl}$ & & & \\
\hline
\end{tabular}

Figure 3. Image of the droplets of distilled water and $3.5 \% \mathrm{NaCl}$ on 1045 steel, $\mathrm{Ni}$ coating, and Ni-Gr coatings.

The measured contact angle, as well as the calculated surface energy values of 1045 steel, Ni coating, Ni-Gr coating, are given in Table 3. These measurements were used in the Fowkes' surface energy calculations to obtain two linear equations (one equation for each liquid) correlating the dispersive $\left(\sigma_{\mathrm{S}}^{\mathrm{D}}\right)$ and polar $\left(\sigma_{\mathrm{S}}^{\mathrm{P}}\right)$ components of surface energy for the given solid surface. The variation in calculated surface energy values with its components for each surface are shown in Figure 4.

The results indicate that $\mathrm{Ni}-\mathrm{Gr}$ coating had overall surface energy, which was about $82.84 \%$ less than the Ni coating, while $75.6 \%$ less than the steel substrate. The presence of graphene was found to decrease the polar component of surface energy significantly than the dispersive component. It can also be observed that even though $\mathrm{Ni}$ and $\mathrm{Ni}-\mathrm{Gr}$ coating shows a hydrophobic nature, they can show about a $38 \%$ decrease in contact angle when wetted by a $3.5 \% \mathrm{NaCl}$ solution. Thus, the dispersive and polar components impact on the surface energy was evident from these data. The contact angle did 
not depend on the thickness of single-, bi-, and multilayer Gr $[53,54]$. Hence, small quantities of $\mathrm{Gr}$ present on the surface were sufficient to influence the surface energy.

Table 3. Average contact angle of distilled water and $3.5 \% \mathrm{NaCl}$ on 1045 steel, Ni coating, and $\mathrm{Ni}-\mathrm{Gr}$ coating.

\begin{tabular}{|c|c|c|c|c|c|c|c|}
\hline \multirow{2}{*}{ Surface } & \multicolumn{2}{|c|}{ Contact Angle $(\theta)$} & \multicolumn{2}{|c|}{ Surface Energy (mJ/m²) } & \multirow{2}{*}{$\begin{array}{l}\text { Overall Surface } \\
\text { Energy }\left(\mathrm{mJ} / \mathrm{m}^{2}\right)\end{array}$} & \multicolumn{2}{|c|}{$\begin{array}{l}\text { Adhesive Energy } \\
\left(\mathrm{mJ} / \mathrm{m}^{2}\right)\end{array}$} \\
\hline & $\begin{array}{c}\text { Distilled } \\
\text { Water }\end{array}$ & $\begin{array}{r}3.5 \% \\
\mathrm{NaCl}\end{array}$ & $\begin{array}{l}\text { Dispersive } \\
\text { Component }\end{array}$ & $\begin{array}{c}\text { Polar } \\
\text { Component }\end{array}$ & & $\begin{array}{c}\text { Distilled } \\
\text { Water }\end{array}$ & $3.5 \% \mathrm{NaCl}$ \\
\hline 1045 steel & 70.6 & 66.3 & $26.83(26 \%)$ & $77.44(74 \%)$ & $104.27(100 \%)$ & 2.97 & 2.58 \\
\hline Ni Coat & 95 & 58.5 & $18.06(12 \%)$ & $129.96(88 \%)$ & $148.02(100 \%)$ & 13.52 & 12.75 \\
\hline Ni-Gr Coat & 86 & 52.9 & $5.15(20 \%)$ & $20.25(80 \%)$ & $25.4(100 \%)$ & 11.92 & 12.53 \\
\hline
\end{tabular}

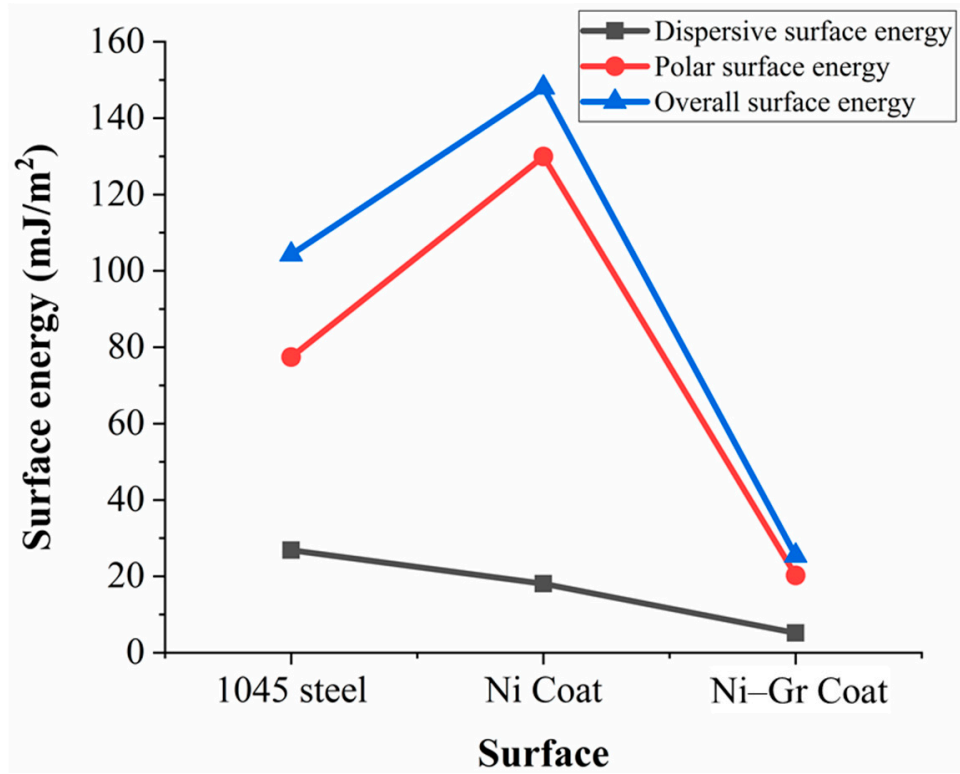

Figure 4. Surface energy and its components (dispersive and polar) calculated for 1045 steel, Ni coating, and $\mathrm{Ni}-\mathrm{Gr}$ coating.

According to Fowkes, dispersion interactions relate to London dispersion, arising from the electron dipole fluctuations, and the polar interactions. The low polar surface energy, in addition to the hydrophobic nature of $\mathrm{Ni}-\mathrm{Gr}$ coatings, indicates that the London dispersion forces are weaker at the coating-fluid interface [55]. This shows that even though fluids with high dispersion surface energy can wet the Ni-Gr coating, the adhesion energy between the fluid and the surface can be low as can be observed in Table 3. This wetting property of Ni-Gr coating was significant when used in lubricated environments where high wettability with low polar surface energy surfaces was beneficial.

\subsection{Hardness}

Nanoindentations tests were performed on the 1045 steel, Ni coating, and Ni-Gr coating using a Hysitron Triboindenter T1950 with Berkovich probe. A maximum force of $10 \mathrm{mN}$ was applied to measure the hardness of the substrate and coatings. The hardness of the surfaces of substrates and the coatings are given in Table 4. A maximum indentation depth of $0.283 \mu \mathrm{m}$ was observed during the indentations. The hardness of the substrates was also compared against the hardness of the counter body, $\mathrm{SiN}$ ball. The surface of the counter body was over $40 \%$ harder than the $\mathrm{Ni}$ and Ni-Gr coatings. Considering this large difference in hardness between the surface and the counter body, the plowing effect of the counter body should lead to abrasive wear on the surface during sliding. It can be observed that the steel surface had a low hardness as compared to the coatings, while both $\mathrm{Ni}$ and $\mathrm{Ni}-\mathrm{Gr}$ coatings had similar hardness. The increased hardness indicates that impervious and strong bonding of 
coating was obtained on the substrate. The similar hardness of both $\mathrm{Ni}$ and $\mathrm{Ni}-\mathrm{Gr}$ coatings also shows that graphene in low volume fraction did not necessarily change the mechanical properties of the coating. Additionally, the large standard deviation (0.949) in the hardness of Ni coating as compared to the Ni-Gr coating might be due to the minor inconsistencies in the electrodeposited layers of $\mathrm{Ni}$. These inconsistencies might have been minimized by the addition of $\mathrm{Gr}$ where the standard deviation of hardness was only 0.425 . These observations indicate that $\mathrm{Gr}$ was a useful tribological material to modify the surface energy with enhanced structural homogeneity of the Ni-Gr electrodeposit.

Table 4. Hardness of steel substrate and the coatings.

\begin{tabular}{ccc}
\hline Surface & H (GPa) & Std. Dev. \\
\hline 1045 steel & 4.632 & 0.443 \\
Ni Coat & 6.606 & 0.949 \\
Ni-Gr Coat & 6.769 & 0.425 \\
SiN ball & 10.82 & 0.396 \\
\hline
\end{tabular}

\subsection{Friction and Wear}

Reciprocating sliding tests were performed to understand the friction and wear behavior of coating in correlation with the surface energy. The coefficient of friction and wear data were recorded by sliding SiN ceramic ball over the $1045 \mathrm{steel}$, Ni coated, and Ni-Gr coated surfaces. A normal load of $2 \mathrm{~N}$ on the ceramic ball of $3 \mathrm{~mm}$ diameter was applied over a sliding distance of $4200 \mathrm{~m}$. The maximum Hertzian contact pressure under the static condition at the interface of the tribo-pair, SiN and 1045 steel, was calculated to be $1432.5 \mathrm{MPa}$ with an expected maximum penetration depth of $0.012 \mathrm{~mm}$ [56]. The evolution of the coefficient of friction (COF) during sliding is shown in Figure 5. An average COF of $0.42 \pm 0.06,0.372 \pm 0.09$, and $0.194 \pm 0.04$ was observed for 1045 steel, Ni coating, and Ni-Gr coating, respectively. It can be observed that as sliding progressed, the COF increased for 1045 steel $(18 \%$ increase over a distance of $4200 \mathrm{~mm})$ and the Ni coated surface $(12 \%$ increase over a distance of $4200 \mathrm{~mm}$ ), while it decreased by $11 \%$ for the $\mathrm{Ni}-\mathrm{Gr}$ coating.

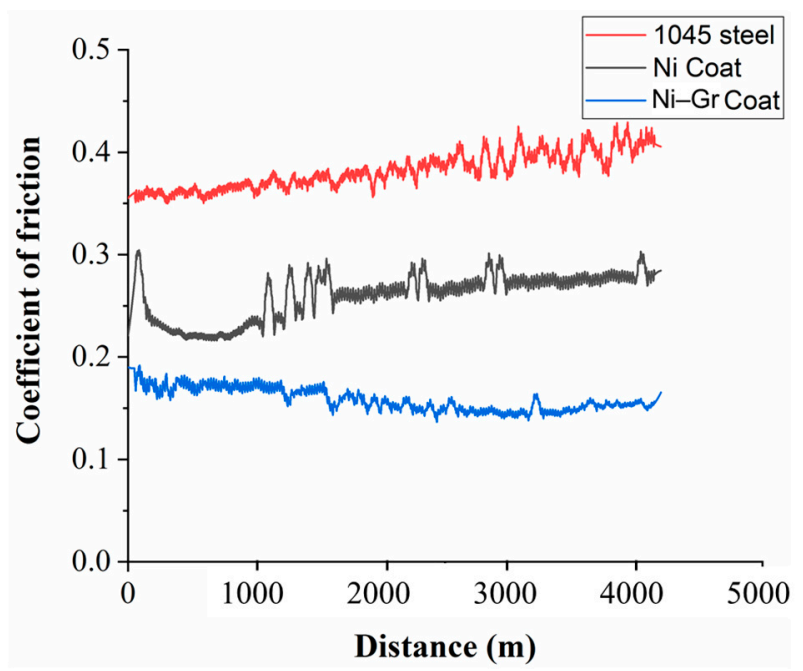

Figure 5. Evolution of the coefficient of friction when sliding on 1045 steel and coated surfaces.

The sliding conditions generate wear debris of varying sizes depending on the surface. In the case of 1045 steel, the wear has been shown to yield micro-sized particles, which can enter the asperity interface and induce a degenerative two-body and third-body-effect [57-60]. These micro-sized particles are less spherical and abrade the contact surface. Thus, the wear mechanisms under such situations would be abrasive wear. In the case of the Ni coating, the slow electrodeposition led to high nucleation with small refined grains that allowed it to generate sub-micron sized particles during wear. 
These sub-micron sized particles led to being more spherical that will roll off easily at the interface without abrading the surfaces, leading to a stable COF as the sliding progresses (after $2900 \mathrm{~m}$ ). Finally, on the Ni-Gr coated surface the wear (after $2000 \mathrm{~m}$ of sliding) led to the exfoliation of graphene from the coating allowing the nanosized particles to enter the asperity contact, thus reducing asperity variations. The low surface energy of $\mathrm{Gr}$ enabled the $\mathrm{Ni}-\mathrm{Gr}$ coating to have minimal adhesive friction, which was a resultant of the low polar surface energy for the coating. Further, Gr is a solid lubricant that helped easy shearing and reduced COF drastically. Additionally, the low surface energy of the of $\mathrm{Ni}-\mathrm{Gr}$ coating aided in reducing the adhesion of $\mathrm{Gr}$ at the asperity interfaces, which provided for a low and consistent COF during sliding.

The wear depth observed after the reciprocating sliding tests on each surface is shown in Figure 6. The figure shows the 2D cross-section profile and 3D wear track profile after sliding a distance of $4200 \mathrm{~m}$. In the present tribo-system, the wear coefficient of 1045 steel surface was $3.31 \times 10^{-10}, \mathrm{Ni}$ coating was $2.95 \times 10^{-11}, \mathrm{Ni}-\mathrm{Gr}$ coating was $1.51 \times 10^{-11}$, and the SiN counter body was $1.93 \times 10^{-13}$. The profile of 1045 steel shown in Figure 6a indicates a wear depth of $0.36 \mu \mathrm{m}$ with pits and embedded wear particles along the wear track. In order to further investigate the wear particle size generated during sliding on each substrate surface, the wear tracks were observed under a scanning electron microscope (SEM). The SEM images of the wear particles along the wear track can be observed in Figure $7 \mathrm{a}-\mathrm{c}$. The generation of large micron-sized wear particles (Figure 7a) during sliding causes entrapment of the particles at the asperity interface, which either led to pitting or embedding of the particle on the surface during repeated sliding. Since, steel exhibited moderately high surface energy with similar contact angles for distilled water and $3.5 \% \mathrm{NaCl}$, hence it could be expected to be susceptible to corrosion and tribocorrosion [42,61].

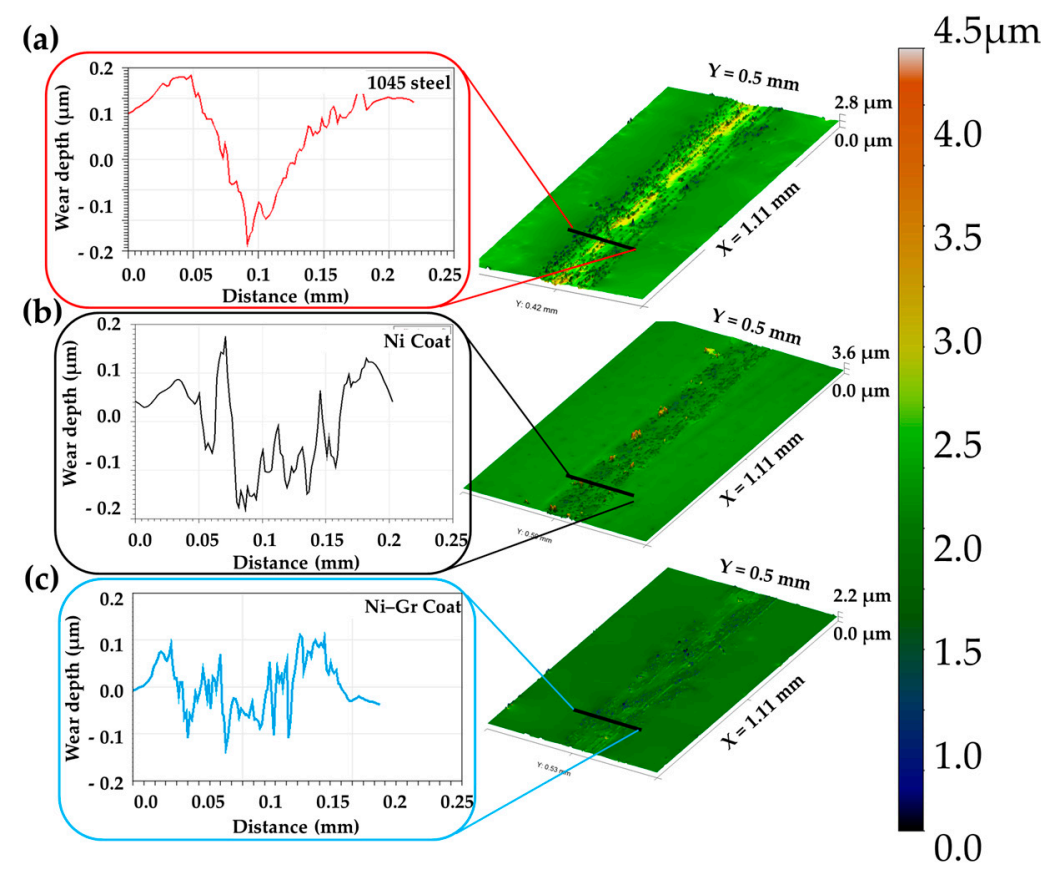

Figure 6. Wear depth and wear track profiles of (a) 1045 steel, (b) Ni Coating, and (c) Ni-Gr coating.

The wear profiles on $\mathrm{Ni}$ and Ni-Gr coatings are shown in Figure $6 b, c$ respectively. The Ni coating exhibited a wear depth of $\sim 0.16 \mu \mathrm{m}$ with large built-up edges along the wear track (Figure $6 \mathrm{~b}$ ). The build-up edges during wear on the Ni coating was mainly due to the high polar surface energy of $\mathrm{Ni}$. The high polar surface energy caused the adhesion of submicron-sized wear particles (Figure $7 \mathrm{~b}$ ) that led to the formation of buildup edges over the length of sliding. The Ni-Gr coating, on the other hand, exhibited a wear track of depth $<0.1 \mu \mathrm{m}$ and a width that was nearly $25 \%$ less than the 1045 steel or Ni coating. The wear debris along the wear track of Ni-Gr surface was much smaller than those 
found on the Ni surface (Figure 7c). It was clear from the SEM images that 1045 steel substrate without any coating generated large micron-sized particles while the Ni-coat generated sub-micron sized wear particles. The Ni-Gr-coat exhibited minimal wear while generating sub-micron to nano-sized wear particles [62]. There was no particle adhesion found on the counter body (SiN ball) as can be observed in Figure 7a-c (ball tip).

(a)

(b)

(c)
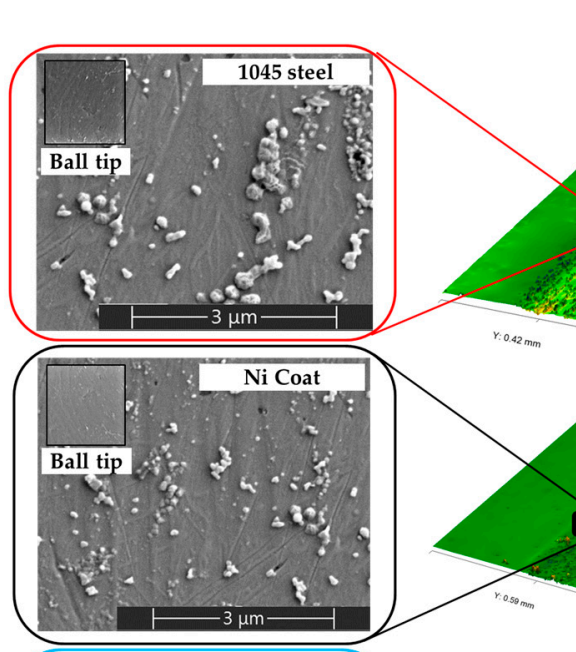

$r: 0.42 \mathrm{~mm}$
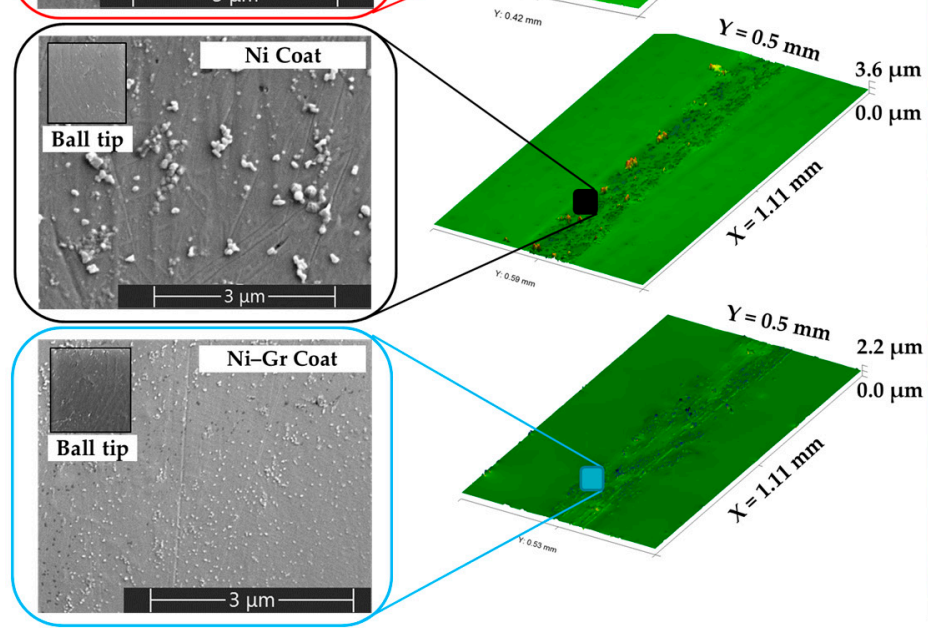

$4.5 \mu \mathrm{m}$

4.0

1.5

1.0

0.0

Figure 7. SEM images of the wear particles around the wear track of (a) 1045 steel, (b) Ni coating, and $(\mathbf{c}) \mathrm{Ni}-\mathrm{Gr}$ coating.

Observing the wear profiles and wear particles generated during sliding on the $\mathrm{Ni}$ and $\mathrm{Ni}-\mathrm{Gr}$ coating, it is evident that the addition of $\mathrm{Gr}$ to Ni matrix can reduce the wear while providing low friction. This behavior can be attributed to the low surface energy of Ni-Gr surface, which reduces the adhesive forces between the wear particles and surface. The reduced adhesive forces result in a reduction in wear particle size and its agglomeration as can be observed in Figure 7c. When the dispersion of a liquid or solid lubricant (such as Gr particle) occurs during sliding on a surface, it is restrained by weak London interactions, which were enough to provide the lubrication effect. The generation of small sub-micron to nano-sized wear particles was a resultant of the low adhesive forces, which prevented embedding of wear particles at the tribo-interface during sliding. Hence, as the Gr exfoliated during sliding provided a well-lubricated tribo-interface without any agglomeration of particles or built-up edges.

\subsection{Wear Mechanisms}

To better understand the wear mechanisms that led to the observed wear profiles and wear debris, a phenomenological model describing the generation of wear debris and their interaction at the tribo-interface is shown in Figure 8. It can be observed in Figure 8a that sliding between the counter material and 1045 steel surface generated micron-sized wear particles through two-body abrasion mechanism. These wear particles get trapped at the tribo-interface during sliding leading to three-body abrasive wear particle that further generated micron-sized irregular shaped wear debris. Such three-body wear debris tended to increase the abrading effect further, leading to deep wear tracks. 
Additionally, the high surface energy of the steel surface could increase the interaction of these wear particles at the tribo-interface.
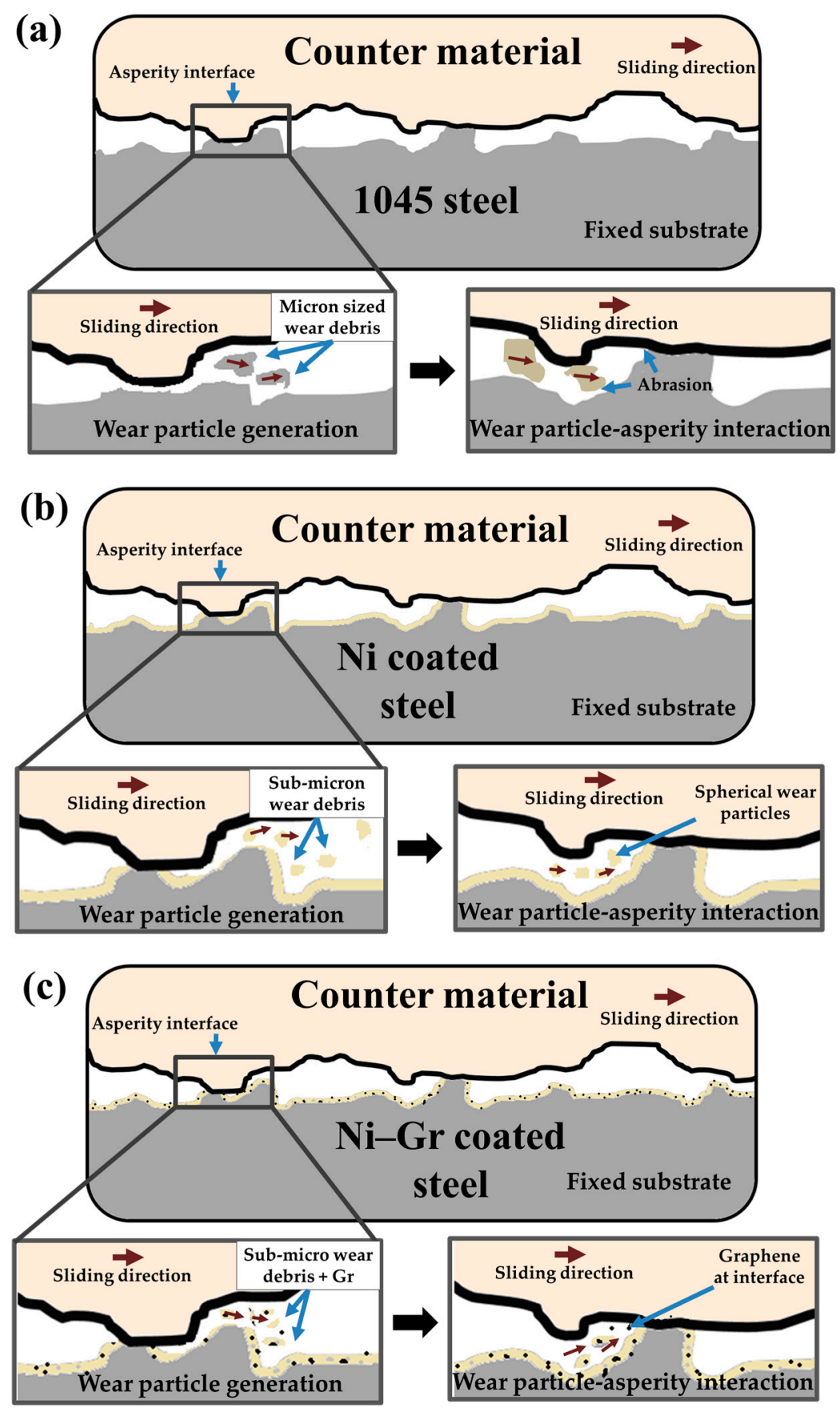

Figure 8. Wear mechanism model during sliding of silicon nitride counter body against (a) 1045 steel, (b) Ni coated, and (c) Ni-Gr coated surfaces.

When the steel surface is coated with either $\mathrm{Ni}$ coating or $\mathrm{Ni}-\mathrm{Gr}$ composite coating the surface energy interactions between the counter body and the coated surface changes, leading to unique wear mechanisms. Figure $8 \mathrm{~b}$ describes the wear mechanism when sliding occurs between the counter body and Ni-coated steel surface. As sliding progresses the two-body abrasion generated sub-micron spherical wear particles, which were small enough to enter the asperity valleys. Though the overall surface energy of the Ni coating was higher than the 1045 steel surface, the dispersive surface energy of the Ni coating was lower. The low dispersive surface energy reduced the adhesive nature of the 
$\mathrm{Ni}$ wear particles. This physical nature of the wear particles in combination with the surface energy properties of the Ni coating led to reduced friction and abrasion at the tribo-interface. When sliding occurred between the counter body and Ni-Gr coated surface, the wear mechanism was similar to that observed for the Ni coating. In addition, there was also $\mathrm{Gr}$ exfoliation from the coating during sliding (Figure 8c). The structure of the graphene helped to easy shearing and further reduced the frictional force, wear rate, and debris formation. Hence, even a low concentration of $\mathrm{Gr}$ in the composite coating could enhance the tribological behavior of the surface.

\section{Conclusions}

The following conclusions could be drawn from the present study:

- The surface roughness and profile data indicated an excellent finish of electrodeposit coatings with a surface roughness that corresponded to the substrate surface.

- $\mathrm{Ni-Gr}$ coating had overall surface energy, which was about $82.84 \%$ less than the Ni coating, while $75.6 \%$ less than the steel substrate.

- The presence of graphene was found to decrease the polar component of surface energy significantly than the dispersive component.

- Fluids with high dispersion surface energy could wet the Ni-Gr coating, but the adhesion energy between the fluid and the surface could be low.

- The addition of $\mathrm{Gr}$ to Ni matrix was found to reduce the wear while providing low friction.

- The COF increased for 1045 steel (18\% increase) and the Ni coated surface (12\% increase), while it decreased by $11 \%$ for the $\mathrm{Ni}-\mathrm{Gr}$ coating.

- Wear on Ni-Gr coated surface led to the exfoliation of graphene from the coating allowing the nanosized particles to enter the asperity contact and reduce the COF.

- The low surface energy of Ni-Gr coating was found to decrease the adhesive forces between the wear particles and surface.

Author Contributions: Conceptualization, A.S., P.K., and P.L.M.; Methodology, A.S., P.K., and A.H.; Software, A.S.; Validation, A.S., and A.H.; formal analysis, A.S., P.K., M.M., and P.L.M.; Investigation, A.S., P.K., and P.L.M.; Resources, M.M., and P.L.M.; Data curation, A.S.; writing-original draft preparation, A.S.; writing-review and editing, A.S., P.K., and P.L.M.; Visualization, A.S.; Supervision, M.M., and P.L.M.; Project administration, M.M., and P.L.M.

Funding: This research received no external funding.

Acknowledgments: The authors appreciate the facility and financial support by startup funding from the Department of Mechanical Engineering, and the Department of Chemical and Materials Engineering at the University of Nevada, Reno.

Conflicts of Interest: The authors declare no conflict of interest.

\section{References}

1. Góral, A.; Lityńska-Dobrzyńska, L.; Kot, M. Effect of Surface Roughness and Structure Features on Tribological Properties of Electrodeposited Nanocrystalline Ni and Ni/ $\mathrm{Al}_{2} \mathrm{O}_{3}$ Coatings. J. Mater. Eng. Perform. 2017, 26, 2118-2128. [CrossRef]

2. Allahyarzadeh, M.H.; Aliofkhazraei, M.; Rezvanian, A.R.; Torabinejad, V.; Sabour Rouhaghdam, A.R. Ni-W electrodeposited coatings: Characterization, properties and applications. Surf. Coat. Technol. 2016, 307, 978-1010. [CrossRef]

3. Ali, E. Solid Lubricants and Self-Lubricating Films. In Modern Tribology Handbook, Two Volume Set; CRC Press: Boca Raton, FL, USA, 2000. [CrossRef]

4. Donnet, C.; Erdemir, A. Historical developments and new trends in tribological and solid lubricant coatings. Surf. Coat. Technol. 2004, 180-181, 76-84. [CrossRef] 
5. Sadeghinezhad, E.; Mehrali, M.; Saidur, R.; Mehrali, M.; Tahan Latibari, S.; Akhiani, A.R.; Metselaar, H.S.C. A comprehensive review on graphene nanofluids: Recent research, development and applications. Energy Convers. Manag. 2016, 111, 466-487. [CrossRef]

6. Rasheed, A.K.; Khalid, M.; Rashmi, W.; Gupta, T.C.S.M.; Chan, A. Graphene based nanofluids and nanolubricants-Review of recent developments. Renew. Sustain. Energy Rev. 2016, 63, 346-362. [CrossRef]

7. Saurín, N.; Sanes, J.; Bermúdez, M.-D. New Graphene/Ionic Liquid Nanolubricants. Mater. Today Proc. 2016, 3, S227-S232. [CrossRef]

8. Gusain, R.; Mungse, H.P.; Kumar, N.; Ravindran, T.R.; Pandian, R.; Sugimura, H.; Khatri, O.P. Covalently attached graphene-ionic liquid hybrid nanomaterials: Synthesis, characterization and tribological application. J. Mater. Chem. A 2016, 4, 926-937. [CrossRef]

9. Bandeira, P.; Monteiro, J.; Baptista, A.M.; Magalhães, F.D. Influence of oxidized graphene nanoplatelets and [DMIM][NTf2] ionic liquid on the tribological performance of an epoxy-PTFE coating. Tribol. Int. 2016, 97, 478-489. [CrossRef]

10. Zhao, J.; He, Y.; Wang, Y.; Wang, W.; Yan, L.; Luo, J. An investigation on the tribological properties of multilayer graphene and MoS2 nanosheets as additives used in hydraulic applications. Tribol. Int. 2016, 97, 14-20. [CrossRef]

11. Ramón-Raygoza, E.D.; Rivera-Solorio, C.I.; Giménez-Torres, E.; Maldonado-Cortés, D.; Cardenas-Alemán, E.; Cué-Sampedro, R. Development of nanolubricant based on impregnated multilayer graphene for automotive applications: Analysis of tribological properties. Powder Technol. 2016, 302, 363-371. [CrossRef]

12. Blanco, D.; González, R.; Viesca, J.L.; Fernández-González, A.; Bartolomé, M.; Battez, A.H. Antifriction and antiwear properties of an ionic liquid with fluorine-containing anion used as lubricant additive. Tribol. Lett. 2017, 65, 66. [CrossRef]

13. Dorri Moghadam, A.; Omrani, E.; Menezes, P.L.; Rohatgi, P.K. Mechanical and tribological properties of self-lubricating metal matrix nanocomposites reinforced by carbon nanotubes (CNTs) and graphene-A review. Compos. Part B Eng. 2015, 77, 402-420. [CrossRef]

14. Tabandeh-Khorshid, M.; Omrani, E.; Menezes, P.L.; Rohatgi, P.K. Tribological performance of self-lubricating aluminum matrix nanocomposites: Role of graphene nanoplatelets. Eng. Sci. Technol. Int. J. 2016, 19, 463-469. [CrossRef]

15. Kasar, A.K.; Xiong, G.; Menezes, P.L. Graphene-Reinforced Metal and Polymer Matrix Composites. JOM 2018, 70, 829-836. [CrossRef]

16. Kasar, A.K.; Menezes, P.L. Synthesis and recent advances in tribological applications of graphene. Int. J. Adv. Manuf. Technol. 2018, 97, 3999-4019. [CrossRef]

17. Omrani, E.; Menezes, L.P.; Rohatgi, K.P. Effect of Micro- and Nano-Sized Carbonous Solid Lubricants as Oil Additives in Nanofluid on Tribological Properties. Lubricants 2019, 7, 25. [CrossRef]

18. Omrani, E.; Rohatgi, P.K.; Menezes, P.L. Tribology and Applications of Self-Lubricating Materials; CRC Press: Boca Raton, FL, USA, 2017.

19. Kumar, C.M.P.; Venkatesha, T.V.; Shabadi, R. Preparation and corrosion behavior of Ni and Ni-graphene composite coatings. Mater. Res. Bull. 2013, 48, 1477-1483. [CrossRef]

20. Algul, H.; Tokur, M.; Ozcan, S.; Uysal, M.; Cetinkaya, T.; Akbulut, H.; Alp, A. The effect of graphene content and sliding speed on the wear mechanism of nickel-graphene nanocomposites. Appl. Surf. Sci. 2015, 359, 340-348. [CrossRef]

21. Berlia, R.; Punith Kumar, M.K.; Srivastava, C. Electrochemical behavior of Sn-graphene composite coating. RSC Adv. 2015, 5, 71413-71418. [CrossRef]

22. Jiang, K.; Li, J.; Liu, J. Electrochemical codeposition of graphene platelets and nickel for improved corrosion resistant properties. RSC Adv. 2014, 4, 36245-36252. [CrossRef]

23. Ren, Z.; Meng, N.; Shehzad, K.; Xu, Y.; Qu, S.; Yu, B.; Luo, J.K. Mechanical properties of nickel-graphene composites synthesized by electrochemical deposition. Nanotechnology 2015, 26, 065706. [CrossRef] [PubMed]

24. Li, J.; An, Z.; Wang, Z.; Toda, M.; Ono, T. Pulse-reverse electrodeposition and micromachining of graphene-nickel composite: An efficient strategy toward high-performance microsystem application. ACS Appl. Mater. Interfaces 2016, 8, 3969-3976. [CrossRef] [PubMed]

25. Chen, L.Y.; Konishi, H.; Fehrenbacher, A.; Ma, C.; Xu, J.Q.; Choi, H.; Xu, H.F.; Pfefferkorn, F.E.; Li, X.C. Novel nanoprocessing route for bulk graphene nanoplatelets reinforced metal matrix nanocomposites. Scr. Mater. 2012, 67, 29-32. [CrossRef] 
26. Lee, S.-K.; Jang, H.Y.; Jang, S.; Choi, E.; Hong, B.H.; Lee, J.; Park, S.; Ahn, J.-H. All Graphene-Based Thin Film Transistors on Flexible Plastic Substrates. Nano Lett. 2012, 12, 3472-3476. [CrossRef] [PubMed]

27. Wang, C.; Brown, G.O.; Burris, D.L.; Korley, L.T.J.; Epps, T.H. Coating Architects: Manipulating Multiscale Structures To Optimize Interfacial Properties for Coating Applications. ACS Appl. Polym. Mater. 2019. [CrossRef]

28. Jokari-Sheshdeh, M.; Mahboubi, F.; Dehghani, K. Structure and tribological behavior of diamond-like carbon coatings deposited on the martensitic stainless steel: The influence of gas composition and temperature. Diam. Relat. Mater. 2018, 81, 77-88. [CrossRef]

29. Tysoe, W.T. 17 Surface Chemistry at the Tribological Interface. Surfactants Tribol. 2016, 2, 437.

30. Emerson, J.A.; Garabedian, N.T.; Burris, D.L.; Furst, E.M.; Epps, T.H. Exploiting Feedstock Diversity To Tune the Chemical and Tribological Properties of Lignin-Inspired Polymer Coatings. ACS Sustain. Chem. Eng. 2018, 6, 6856-6866. [CrossRef]

31. Tripathi, M.; Awaja, F.; Paolicelli, G.; Bartali, R.; Iacob, E.; Valeri, S.; Ryu, S.; Signetti, S.; Speranza, G.; Pugno, N.M. Tribological characteristics of few-layer graphene over Ni grain and interface boundaries. Nanoscale 2016, 8, 6646-6658. [CrossRef]

32. Low, C.T.J.; Wills, R.G.A.; Walsh, F.C. Electrodeposition of composite coatings containing nanoparticles in a metal deposit. Surf. Coat. Technol. 2006, 201, 371-383. [CrossRef]

33. Szeptycka, B.; Gajewska-Midzialek, A.; Babul, T. Electrodeposition and corrosion resistance of Ni-Graphene composite coatings. J. Mater. Eng. Perform. 2016, 25, 3134-3138. [CrossRef]

34. Pagnanelli, F.; Altimari, P.; Bellagamba, M.; Granata, G.; Moscardini, E.; Schiavi, P.G.; Toro, L. Pulsed electrodeposition of cobalt nanoparticles on copper: Influence of the operating parameters on size distribution and morphology. Electrochim. Acta 2015, 155, 228-235. [CrossRef]

35. Topolovec, S.; Krenn, H.; Würschum, R. Enhanced magnetic moment of ultrathin Co films measured by in situ electrodeposition in a SQUID. J. Magn. Magn. Mater. 2016, 397, 96-100. [CrossRef]

36. Ibrahim, M.A.M.; Al Radadi, R.M. Noncrystalline cobalt coatings on copper substrates by electrodeposition from complexing acidic glycine baths. Mater. Chem. Phys. 2015, 151, 222-232. [CrossRef]

37. Abou-Krisha, M.M. Influence of Ni2+ concentration and deposition potential on the characterization of thin electrodeposited Zn-Ni-Co coatings. Mater. Chem. Phys. 2011, 125, 621-627. [CrossRef]

38. Jabbar, A.; Yasin, G.; Khan, W.Q.; Anwar, M.Y.; Korai, R.M.; Nizam, M.N.; Muhyodin, G. Electrochemical deposition of nickel graphene composite coatings: Effect of deposition temperature on its surface morphology and corrosion resistance. RSC Adv. 2017, 7, 31100-31109. [CrossRef]

39. Yaghoubinezhad, Y.; Afshar, A. Design of Experiments for Pulse Reverse Electrodeposition of Graphene Oxide toward Hydrogen Evolution Reaction. ECS J. Solid State Sci. Technol. 2015, 4, M7-M17. [CrossRef]

40. Tao, S.; Li, D.Y. Tribological, mechanical and electrochemical properties of nanocrystalline copper deposits produced by pulse electrodeposition. Nanotechnology 2006, 17, 65. [CrossRef]

41. Abou-Krisha, M.M. Electrochemical studies of zinc-nickel codeposition in sulphate bath. Appl. Surf. Sci. 2005, 252, 1035-1048. [CrossRef]

42. Nazir, M.H.; Khan, Z.A.; Saeed, A.; Siddaiah, A.; Menezes, P.L. Synergistic wear-corrosion analysis and modelling of nanocomposite coatings. Tribol. Int. 2018, 121, 30-44. [CrossRef]

43. Rapp, B.E. Chapter 22-Measuring Surface Tension and Free Surface Energy. In Microfluidics: Modelling, Mechanics and Mathematics; Rapp, B.E., Ed.; Elsevier: Oxford, UK, 2017; pp. 453-465.

44. Pimenta, M.A.; Dresselhaus, G.; Dresselhaus, M.S.; Cançado, L.G.; Jorio, A.; Saito, R. Studying disorder in graphite-based systems by Raman spectroscopy. Phys. Chem. Chem. Phys. 2007, 9, 1276-1290. [CrossRef] [PubMed]

45. Ferrari, A.C.; Meyer, J.C.; Scardaci, V.; Casiraghi, C.; Lazzeri, M.; Mauri, F.; Piscanec, S.; Jiang, D.; Novoselov, K.S.; Roth, S.; et al. Raman Spectrum of Graphene and Graphene Layers. Phys. Rev. Lett. 2006, 97, 187401. [CrossRef] [PubMed]

46. Gupta, A.; Chen, G.; Joshi, P.; Tadigadapa, S.; Eklund. Raman Scattering from High-Frequency Phonons in Supported n-Graphene Layer Films. Nano Lett. 2006, 6, 2667-2673. [CrossRef] [PubMed]

47. Childres, I.; Jauregui, L.A.; Park, W.; Cao, H.; Chen, Y.P. Raman spectroscopy of graphene and related materials. New Dev. Photon Mater. Res. 2013, 19, 1-20. 
48. Yu, Q.; Jauregui, L.A.; Wu, W.; Colby, R.; Tian, J.; Su, Z.; Cao, H.; Liu, Z.; Pandey, D.; Wei, D. Control and characterization of individual grains and grain boundaries in graphene grown by chemical vapour deposition. Nat. Mater. 2011, 10, 443. [CrossRef] [PubMed]

49. Kong, A.N.G.; Gong, B.-K.; Wang, G.; Cui, H.-W. Influence of surface roughness of substrate on the properties of Ni-Co-Fe electrodeposition coating on copper. Surf. Rev. Lett. 2017, 25, 1850120. [CrossRef]

50. Nazir, M.H.; Khan, Z. Maximising the interfacial toughness of thin coatings and substrate through optimisation of defined parameters. Int. J. Comput. Methods Exp. Meas. 2015, 3, 316-328. [CrossRef]

51. Fowkes, F.M. Attractive forces at interfaces. Ind. Eng. Chem. 1964, 56, 40-52. [CrossRef]

52. Busscher, H.J.; Van Pelt, A.W.J.; De Boer, P.; De Jong, H.P.; Arends, J. The effect of surface roughening of polymers on measured contact angles of liquids. Colloids Surf. 1984, 9, 319-331. [CrossRef]

53. Lin, J.; Wang, L.; Chen, G. Modification of Graphene Platelets and their Tribological Properties as a Lubricant Additive. Tribol. Lett. 2011, 41, 209-215. [CrossRef]

54. Shin, Y.J.; Wang, Y.; Huang, H.; Kalon, G.; Wee, A.T.S.; Shen, Z.; Bhatia, C.S.; Yang, H. Surface-Energy Engineering of Graphene. Langmuir 2010, 26, 3798-3802. [CrossRef] [PubMed]

55. French, R.H. Origins and applications of London dispersion forces and Hamaker constants in ceramics. J. Am. Ceram. Soc. 2000, 83, 2117-2146. [CrossRef]

56. Puttock, M.J.; Thwaite, E.G. Elastic compression of spheres and cylinders at point and line contact. In Elastic Compression of Spheres and Cylinders at Point and Line Contact; Puttock, M.J., Thwaite, E.G., Eds.; Commonwealth Scientific and Industrial Research Organization: Melbourne, Australia, 1969; p. 64.

57. Coronado, J.J. Abrasive Size Effect on Friction Coefficient of AISI 1045 Steel and 6061-T6 Aluminium Alloy in Two-Body Abrasive Wear. Tribol. Lett. 2015, 60, 40. [CrossRef]

58. Hurricks, P.L. The mechanism of fretting-A review. Wear 1970, 15, 389-409. [CrossRef]

59. Siddaiah, A.; Kasar, K.A.; Khosla, V.; Menezes, L.P. In-Situ Fretting Wear Analysis of Electrical Connectors for Real System Applications. J. Manuf. Mater. Process. 2019, 3, 47. [CrossRef]

60. Reeves, C.J.; Menezes, P.L.; Lovell, M.R.; Jen, T.-C. The Size Effect of Boron Nitride Particles on the Tribological Performance of Biolubricants for Energy Conservation and Sustainability. Tribol. Lett. 2013, 51, 437-452. [CrossRef]

61. Siddaiah, A.; Khan, A.Z.; Ramachandran, R.; Menezes, L.P. Performance Analysis of Retrofitted Tribo-Corrosion Test Rig for Monitoring In Situ Oil Conditions. Materials 2017, 10, 1145. [CrossRef]

62. Menezes, P.L.; Ingole, S.P.; Nosonovsky, M.; Kailas, S.V.; Lovell, M.R. Tribology for scientists and engineers. In Tribology for Scientists and Engineers; Springer: Berlin, Germany, 2013; pp. 9-28. 